Published in final edited form as:

J Electrocardiol. 2013 ; 46(3): 249-255. doi:10.1016/j.jelectrocard.2013.02.006.

\title{
Localization of myocardial scar in patients with cardiomyopathy and left bundle branch block using electrocardiographic Selvester QRS scoring *
}

\author{
Björn Wieslander ${ }^{a, b}$, Katherine C. Wu, MD ${ }^{c}$, Zak Loring, BS ${ }^{d}$, Linus G. Andersson ${ }^{a, b}$, Terry \\ F. Frank ${ }^{c}$, Gary Gerstenblith, $\mathbf{M D}^{\mathrm{c}}$, Gordon F. Tomaselli, MD $^{\mathrm{c}}$, Robert G. Weiss, $\mathbf{M D}^{\mathrm{c}}$, Galen \\ S. Wagner, $\mathbf{M D}^{\mathrm{b}}$, Martin Ugander, MD, PhDa ${ }^{\mathrm{a}}$, and David G. Strauss, MD, $\mathbf{P h D}^{\mathrm{e}}{ }^{*}$ \\ ${ }^{a}$ Cardiac MR Group, Department of Clinical Physiology, Karolinska Institutet and Karolinska \\ University Hospital, Stockholm, Sweden \\ ${ }^{b}$ Duke Clinical Research Institute, Durham, NC, USA \\ 'Division of Cardiology, Department of Medicine, Johns Hopkins Medical Institutions, Baltimore, \\ MD, USA \\ dDuke University School of Medicine, Durham, NC, USA \\ eOffice of Science and Engineering Laboratories, Center for Devices and Radiological Health, \\ United States Food and Drug Administration, Silver Spring, MD, USA
}

\begin{abstract}
Introduction-Outcome of cardiac resynchronization therapy is severely worsened by myocardial scar at the left ventricular (LV) pacing site. We aimed to describe the diagnostic performance of electrocardiographic (ECG) criteria based on the Selvester QRS scoring system, first in localizing myocardial scar and second in screening for any non-septal scar in patients with strictly defined LBBB.
\end{abstract}

\begin{abstract}
Methods and Results-In 39 cardiomyopathy patients with LBBB, 17 with scar, 22 without scar, late gadolinium-enhancement cardiac magnetic resonance images (CMR-LGE) and 12-lead ECGs were analyzed for scar presence in $5 \mathrm{LV}$ wall segments. The ECG criteria with the best diagnostic performance in detecting scar in each segment and in the four non-septal segments together were identified. Criteria for detecting non-septal scar had 75\% (95\% CI: 51\%-90\%) sensitivity, 95\% (78\%-99\%) specificity, $92 \%$ (67\%-99\%) positive predictive value and $84 \%$ (65\%-94\%) negative predictive value. For each individual wall segment, 40\%-60\% sensitivities and $77 \%-100 \%$ specificities were found.
\end{abstract}

\footnotetext{
it Source of funding: The study was supported by the National Heart, Lung, and Blood Institute, National Institutes of Health (HL103812 to K.C.W., HL91062 to G.F.T., and HL61912 to R.G.W.), the DW Reynolds Foundation and the FDA Critical Path Initiative.

*Corresponding author. 10903 New Hampshire Ave 62-1126, Silver Spring, MD 20993, USA. david.strauss@fda.hhs.gov. Disclaimer

The mention of commercial products, their sources, or their use in connection with material reported herein is not to be construed as either an actual or implied endorsement of such products by the U.S. Department of Health and Human Services.

Supplementary data to this article can be found online at http://dx.doi.org/10.1016/j.jelectrocard.2013.02.006.
} 
Conclusions-The 12-lead ECG can convey information about scar presence and location in this population of cardiomyopathy patients with LBBB. ECG screening criteria for scar in potential CRT LV pacing sites were identified. Further exploration is required to determine the clinical utility of the 12-lead ECG in combination with other imaging modalities to screen for scar in potential LV pacing sites in CRT candidates.

\section{Keywords}

Selvester QRS score; Myocardial scar localization; Left bundle branch block; Cardiac resynchronization therapy; Cardiomyopathy

\section{Introduction}

Cardiac resynchronization therapy (CRT) has been shown to reduce heart failure morbidity and mortality in populations with left ventricular ejection fraction (LVEF) $\leq 35 \%$ and prolonged QRS duration. ${ }^{1-4}$ However, many patients do not benefit from CRT. Several studies have shown that presence of left bundle branch block (LBBB) is an important predictor of CRT efficacy. ${ }^{4-6}$ Furthermore, recently proposed strict LBBB criteria ${ }^{7}$ have been found to be a stronger predictor of CRT outcome than the classic LBBB criteria. ${ }^{8}$ In addition, it is recognized that the distribution of myocardial scar is important when selecting a left ventricular (LV) pacing site. ${ }^{9-13}$ Scar at the LV pacing site has been shown to adversely affect clinical outcome. ${ }^{14,15}$ Several studies have found that most (82\%-84\%) CRT LV leads are placed in the lateral wall, ${ }^{11,16,17}$ and that the remainder are distributed among the apical, anterior and inferior wall segments. Therefore it is important to screen for any non-septal scar in candidates for CRT. Thus, an inexpensive and clinically widely available method of screening for and localizing scar could potentially improve patient selection.

Myocardial scar can be assessed by the surface 12-lead electrocardiogram (ECG) using the Selvester QRS scoring system. ${ }^{18}$ This system translates the morphology of the QRS complex into information about myocardial scar presence, size and location. ${ }^{18}$ The accuracy of the score has been previously validated in patients without conduction abnormalities by comparison with post-mortem pathology analysis. ${ }^{19-26}$ The development and physiological background of the Selvester QRS score has been summarized in a recent review article. ${ }^{18}$

Conduction abnormalities such as LBBB have been traditionally believed to obscure ECG signs of infarction. ${ }^{27}$ However, modified versions of the QRS score have recently been shown to accurately quantify scar determined by cardiac magnetic resonance imaging with late gadolinium enhancement (CMR-LGE) in patients with conduction abnormalities, including $\mathrm{LBBB},{ }^{29}$ and to predict response to $\mathrm{CRT} .{ }^{29}$ Further, each criterion in the LBBB version of the QRS score is assigned to one of five LV wall segments in a five-segment LV subdivision model. ${ }^{30}$ However, the diagnostic performance of the Selvester QRS score to localize myocardial scar to specific LV wall segments in the presence of LBBB has not been determined. 


\section{Study aim}

In this study, we aimed to assess the diagnostic performance of the LBBB Selvester QRS score criteria in correctly localizing scar presence in each of the five segments of the $\mathrm{LV}$, as well as in screening for scar in any of the non-septal segments. The performance was determined by identifying the LBBB Selvester QRS score ECG criteria that attain the optimal combination of sensitivity and specificity in individually localizing septal, anterior, lateral, inferior, apical and any non-septal scar, when using CMR-LGE as the gold standard.

\section{Methods}

\section{Patients}

This study was an analysis of all LBBB patients enrolled in the CMR imaging arm of the PROSE-ICD (Prospective Observational Study of Implantable Cardioverter Defibrillator). ${ }^{31-33}$ Enrollment occurred between November 2003 and December 2010. Details of the inclusion and exclusion criteria were previously published. ${ }^{33}$ Patients with LVEF $\leq 35 \%$ scheduled for primary prevention ICD placement according to clinical indications underwent CMR and 12-lead ECG prior to device placement. Among the 235 enrolled patients, we identified 45 with LBBB using recently proposed strict LBBB criteria. ${ }^{7}$ Two of these were excluded due to insufficient ECG recording quality for accurate QRS scoring. One was excluded due to incomplete CMR image coverage of the LV. Three more were excluded due to having CMR-detectable amount of myocardial scar between $1 \%$ and $2 \%$ as explained below in the CMR analysis section. Analysis was performed on the remaining 39 patients.

Both chronic ischemic and non-ischemic cardiomyopathy patients were included. Patients were categorized as having either an ischemic or non-ischemic etiology based on coronary angiographic and prior history of infarction or revascularization. ${ }^{33}$ Patients gave written consent and the study protocol was approved by the Johns Hopkins Institutional Review Board, the Duke Institutional Review Board and FDA Research in Human Subjects Committee.

\section{ECG acquisition and analysis}

ECGs were obtained using a GE Marquette system. Analysis was performed by two independent observers. Disagreements were adjudicated to reach consensus. First, analysis for the presence of LBBB was performed using criteria proposed by Strauss et al. ${ }^{7}$ : $\mathrm{V}_{1}$ terminal negative deflection ( $\mathrm{rS}$ or Q wave), QRS duration $\geq 140 \mathrm{~ms}$ for men ( $\geq 130 \mathrm{~ms}$ for women) and mid-QRS (after $40 \mathrm{~ms}$ ) notching/slurring/slowing in $\geq 2$ of leads $\mathrm{V}_{1}, \mathrm{~V}_{2}, \mathrm{~V}_{5}$, $\mathrm{V}_{6}, 1$ or aVL." Patients who did not fulfill these strict LBBB criteria were excluded ( $n=$ 190).

The LBBB Selvester QRS score criteria (Table 1) were applied to the included patients' ECGs. A detailed guide on how to apply the LBBB Selvester QRS score criteria ${ }^{30}$ was used as a reference during the process of scoring the ECGs. For a more detailed description of the scoring process in the present study, see Appendix A. 


\section{A five-segment LV subdivision model}

In the Selvester QRS scoring system, ${ }^{18}$ each point represents scarring in approximately 3\% of the total LV mass. Each point in the LBBB version is assigned to one of five LV wall segments in a previously described five-segment subdivision model ${ }^{18}$ (Fig. 1). That model is based on a 12-segment model that was developed with consideration of the typical coronary arterial perfusion beds. The specifics of this subdivision model have been published previously. ${ }^{34}$ The anatomical names of some of the five segments were changed in this study compared to previous publications involving the Selvester QRS score to match current standard cardiac imaging nomenclature. ${ }^{35}$ The term "septal" is used instead of "anteroseptal", "anterior" instead of "anterosuperior" and "lateral" instead of "posterolateral." We have consequently re-labeled certain Selvester QRS criteria listed in Table 1. The terms "septal" and "lateral" are used instead of "anterior" and "posterior" as in previous publications involving the Selvester QRS score.

\section{CMR acquisition and analysis}

The CMR protocol has been described previously. ${ }^{28,31-33}$ Between 8 and 15 short-axis slices were analyzed per patient. Slice thicknesses were $8 \mathrm{~mm}$ in all patients and for most patients $(n=31)$ inter-slice spacing was $2 \mathrm{~mm}$. In nine patients the inter-slice spacing was 0 $\mathrm{mm}$ and in two patients the inter-slice spacing was $4 \mathrm{~mm}$.

All CMR-LGE images were analyzed manually to determine whether scar was present, represented by elevated signal intensity (SI) with confirmation in two different views. The scar (LGE) borders were semi-automatically outlined in short-axis slices. Scar areas were divided into "core" and "gray zone" scar using SI as previously described. ${ }^{28}$ Total scar extent was calculated as core LGE $+1 / 2$ gray zone LGE.

The total LV long-axis length, slice thickness and inter-slice spacing thickness were used to determine which slices were in the apical third of the LV. Segmentation into four quadrants was done in the short-axis slices by using the anterior RV insertion as reference point to mark the border between the anterior and septal quadrants. Three other points were $90^{\circ}$ apart and used to mark the borders between the other quadrants (see Fig. 1).

In the slices in the apical third of the LV, the scar volumes for all quadrants were summed to determine the total scar volume in the apical segment. In three cases where the thickness of a slice was deemed to be part in the apical third and part in the middle third of the LV, the scar volumes of the border slices were divided accordingly.

In the basal and mid-slices, the scar volumes for each of the quadrants from each of the slices were summed to determine the total scar volume in each quadrant segment. In patients with inter-slice spacing, the scar volume for each segment was corrected by instead using "scar volume + (scar volume $\times$ spacing/thickness)." Scar extent in each segment was converted to \% of total LV volume. To calculate LV volume, LV mass measured in the CMR-LGE images was divided by the density of myocardium, $1.05 \mathrm{~g} / \mathrm{cm} \cdot{ }^{3,36}$ Segments were considered to be scarred if they contained scar $\geq 3 \%$ the LV mass as quantified by CMR. In the cohort in which we assessed specificity of the Selvester QRS score criteria $(n=$ 22) we only included patients with absence of CMR-detectable myocardial scar. Thus 
patients who had scar detected by CMR-LGE but who did not have $\geq 3 \%$ of the LV mass in any segment were excluded $(n=3)$.

\section{Statistical analysis}

Subsets of LBBB Selvester QRS score criteria that diagnosed scar presence with the maximum combination of sensitivity and specificity were identified for each of the five LV wall segments, respectively, as well as for the four non-septal wall segments together. This was done using a stepwise criteria selection process detailed in Appendix B. In summary, this selection process involved selecting the individual criteria that made the greatest contributions to sensitivity for the criteria subset while maintaining predefined specificity levels. Several subsets of criteria for each LV segment with varying sensitivities and specificities were yielded and an ROC graph (Fig. 2) was used to select the one subset for each LV segment that had the optimal combination of sensitivity and specificity.

\section{Results}

Characteristics of the study cohort $(n=39)$ are shown in Table 2 . Seventeen patients (44\%) had CMR-LGE detected scar $\geq 3 \%$ of the LV volume in at least $1 \mathrm{LV}$ wall segment. There were 16 patients ( $41 \%$ ) with scar $\geq 3 \%$ of the LV volume in at least one of the four nonseptal segments.

The ROC graph that was used for selecting the optimal subset of Selvester scoring criteria for each LV wall segment is shown in Fig. 2. Each candidate criteria subset is represented as a data point in the graph. The subset of criteria for each location that was closest to the upper left corner in the ROC graph was selected as the subset that attained the maximum combination of sensitivity and specificity.

\section{Identified criteria for the individual segments}

For the five individual LV wall segments, subsets of the Selvester QRS score criteria were identified (Table 3) that detected scar with sensitivities ranging from $40 \%$ to $60 \%$ and specificities ranging from $77 \%$ to $100 \%$. The subsets of criteria for the septal, anterior, inferior and apical segments had similar diagnostic performances, whereas the subset for the lateral segment had higher specificity but lower sensitivity. The subset for the lateral segment, consisting of a single QRS score criterion ( $\mathrm{S} / \mathrm{S}^{\prime} \geq 1.5$ in $\mathrm{V}_{2}$ ), had a specificity of $100 \%(22 / 22)$ and a sensitivity of $40 \%(2 / 5)$ which corresponded to positive and negative predictive values of $100 \%(2 / 2)$ and $84 \%$ (22/25), respectively. However, the number of patients with scar in the lateral segment was low $(n=5)$. Examples of ECGs in study subjects that illustrate these Selvester QRS scoring criteria for scar in the lateral LV wall segment are presented in Fig. 3A and B.

\section{Identified criteria for screening of non-septal scar}

A subset of criteria was also identified that detected non-septal scar with $95 \%$ specificity (95\% CI: 78\%-99\%) and 75\% sensitivity (95\% CI: 51\%-90\%), which corresponded to a positive predictive value of $92 \%$ (95\% CI: 67\%-99\%) and a negative predictive value of 84\% (95\% CI: 65\%-94\%) (Table 4). The identified non-septal criteria subset indicates scar 
if any of five criteria are present: $\mathrm{S} / \mathrm{S}^{\prime} \geq 1.5$ in $\mathrm{V}_{2}$ OR R/S $\leq 1$ in lead I OR R/S $\leq 0.5$ in aVL OR Q $\geq 30 \mathrm{~ms}$ in lead II OR Q $\geq 40 \mathrm{~ms}$ in aVF. The $\mathrm{S} / \mathrm{S}^{\prime}$ and $\mathrm{R} / \mathrm{S}$ criteria are further explained in Fig. 3A-D.

\section{Discussion}

The results of this study show that ECG criteria can be used to identify and localize scar in LBBB patients. Furthermore, a set of ECG screening criteria were identified to detect scar in potential CRT LV lead placement sites. The diagnostic performance of the identified nonseptal scar screening criteria (75\% sensitivity, $95 \%$ specificity) is comparable to a set of three normal conduction Selvester QRS score scar screening criteria (77\%-84\% sensitivity for anterior/inferior infarcts respectively and $95 \%$ specificity $)^{19}$ for detecting single infarcts in patients without any type of conduction abnormality.

It is traditionally thought that LBBB confounds ECG diagnosis and localization of myocardial scar. ${ }^{27}$ However, Strauss et al. ${ }^{28}$ showed that chronic myocardial scar could be quantified using the ECG despite the presence of LBBB. In addition, Sweeney et al. ${ }^{29}$ demonstrated that increasing Selvester QRS score predicted decreased response to CRT. The results of the present study further show that the ECG can convey information about scar localization in patients with LBBB.

The lateral wall screening criterion, $S / \mathrm{S}^{\prime} \geq 1.5$ in $\mathrm{V}_{2}$ (illustrated in Fig. $3 \mathrm{~A}$ and $\mathrm{B}$ ), had $100 \%$ specificity and $40 \%$ sensitivity, yielding a positive predictive value of $100 \%$. Potential CRT recipients who meet the lateral screening criterion $\left(S / S^{\prime} \geq 1.5\right.$ in lead $\left.V_{2}\right)$ are thus highly likely to have scar in the lateral wall. However, this result should be interpreted with caution due to the limited number of patients $(n=5)$ with lateral scar in the study population.

Notably, the identified set of screening criteria for non-septal scar $\left(\mathrm{S} / \mathrm{S}^{\prime} \geq 1.5\right.$ in $\mathrm{V}_{2}$ OR R/S $\leq 1$ in lead I OR R/S $\leq 0.5$ in aVL OR Q $\geq 30 \mathrm{~ms}$ in lead II OR Q $\geq 40 \mathrm{~ms}$ in aVF) had 92\%positive (95\%CI: 67\%-99\%) and 84\% negative (95\% CI: 65\%-94\%) predictive values in this cohort. This is of interest since several larger studies ${ }^{11,16,17}$ have shown that while the majority (82\%-84\%) of CRT LV leads are implanted in the lateral wall, the remainder (16\%-18\%) are distributed among the anterior, apical and inferior wall segments.

Even though location of scar can be determined with greater accuracy using other imaging modalities such as CMR-LGE directly, the standard 12-lead ECG as a screening tool has the advantage of being inexpensive, almost universally clinically available and having virtually no contraindications.

There is evidence supporting the hypothesis that one-third of patients are misdiagnosed with LBBB when using conventional LBBB criteria and new strict LBBB criteria have been proposed. ${ }^{7}$ These strict LBBB criteria were used in the current study and were recently shown to be a strong predictor of response to CRT. ${ }^{8}$ To further validate these new strict LBBB criteria, their reproducibility in repeat ECGs could be measured in a future study. 


\section{Limitations}

The major limitation of this study is the size of the study population. However, this is the first study in which location of LBBB scar using the Selvester QRS score has been tested. The number of patients with lateral scar was particularly low, which made the ability of the Selvester QRS score to locate such scars more difficult to evaluate comprehensively. The prevalence of the different scar locations may be different in this cohort than in others, which would affect the positive and negative predictive values. As with all stepwise regression analysis methods, there is an inherent risk of finding correlations that are specific for the population being tested. Therefore the sets of screening criteria identified in this study will need to be confirmed in other populations which were not used to develop the criteria.

\section{Clinical implications}

The major clinical implication of this study is that the 12- lead ECG may be useful in screening for non-septal scar in cardiomyopathy patients with LBBB. This is important because it suggests the potential for the ECG to help elucidate solutions to the clinical problem of identifying CRT candidates with scar in potential LV pacing sites. Today, almost no patients undergo imaging to detect LV scar such as CMR-LGE prior to CRT implantation. Rather than all patients undergoing relatively costly investigations such as CMR-LGE, the 12-lead ECG may potentially be used as a risk-stratifying tool to increase cost-effectiveness by selecting the CRT candidates who would benefit the most from such imaging prior to implantation. This requires further study.

\section{Conclusions}

In conclusion, the results suggest that the majority of non-septal scars can be detected by the 12-lead ECG in the presence of chronic cardiomyopathy and LBBB. The performance of the subsets of screening criteria identified in this study should be confirmed in larger independent populations. The role of the 12-lead ECG in optimizing patient selection for CRT, particularly with regard to its potential to be used for scar screening, should be further investigated.

\section{Supplementary Material}

Refer to Web version on PubMed Central for supplementary material.

\section{Acknowledgments}

The authors gratefully acknowledge Kathy Shuping for practical assistance throughout the completion of the study. Further, the authors would like to thank Prof. Chuck Maynard for his valuable advice on statistics. Use of the custom research software, CINEtool, was obtained through a research agreement between Dr. Wu and GE Healthcare. Dr. Wu receives modest royalties for the licensing rights to use the gray zone methodology described in this article. 


\section{References}

1. Cleland JG, Daubert JC, Erdmann E, et al. Cardiac Resynchronization-Heart Failure Study I: the effect of cardiac resynchronization on morbidity and mortality in heart failure. N Engl J Med. 2005; 352:1539. [PubMed: 15753115]

2. Bristow MR, Saxon LA, Boehmer J, et al. Comparison of Medical Therapy PaDiHFI: cardiacresynchronization therapy with or without an implantable defibrillator in advanced chronic heart failure. N Engl J Med. 2004; 350:2140. [PubMed: 15152059]

3. Moss AJ, Hall WJ, Cannom DS, et al. Investigators M-CT: cardiac-resynchronization therapy for the prevention of heart-failure events. N Engl J Med. 2009; 361:1329. [PubMed: 19723701]

4. Tang AS, Wells GA, Talajic M, et al. Resynchronization-Defibrillation for Ambulatory Heart Failure Trial I: cardiac-resynchronization therapy for mild-to-moderate heart failure. N Engl J Med. 2010; 363:2385. [PubMed: 21073365]

5. Zareba W, Klein H, Cygankiewicz I, et al. Effectiveness of cardiac resynchronization therapy by QRS morphology in the Multicenter Automatic Defibrillator Implantation Trial-Cardiac Resynchronization Therapy (MADIT-CRT). Circulation. 2011; 123:1061. [PubMed: 21357819]

6. Bilchick KC, Kamath S, DiMarco JP, Stukenborg GJ. Bundle-branch block morphology and other predictors of outcome after cardiac resynchronization therapy in Medicare patients. Circulation. 2010; 122:2022. [PubMed: 21041691]

7. Strauss DG, Selvester RH, Wagner GS. Defining left bundle branch block in the era of cardiac resynchronization therapy. Am J Cardiol. 2011; 107:927. [PubMed: 21376930]

8. Mascioli G, Padeletti L, Sassone B, et al. Electrocardiographic criteria of true left bundle branch block: a simple sign to predict a better clinical and instrumental response to CRT. Pacing Clin Electrophysiol. 2012; 35:927. [PubMed: 22651702]

9. Bleeker GB, Kaandorp TA, Lamb HJ, et al. Effect of posterolateral scar tissue on clinical and echocardiographic improvement after cardiac resynchronization therapy. Circulation. 2006; 113:969. [PubMed: 16476852]

10. White JA, Yee R, Yuan X, et al. Delayed enhancement magnetic resonance imaging predicts response to cardiac resynchronization therapy in patients with intraventricular dyssynchrony. $\mathrm{J}$ Am Coll Cardiol. 2006; 48:1953. [PubMed: 17112984]

11. Khan FZ, Virdee MS, Palmer CR, et al. Targeted left ventricular lead placement to guide cardiac resynchronization therapy: the TARGET study: a randomized, controlled trial. J Am Coll Cardiol. 2012; 59:1509. [PubMed: 22405632]

12. Heydari B, Jerosch-Herold M, Kwong RY. Imaging for planning of cardiac resynchronization therapy. JACC Cardiovasc Imaging. 2012; 5:93. [PubMed: 22239899]

13. McAlister FA, Ezekowitz J, Dryden DM, et al. Cardiac resynchronization therapy and implantable cardiac defibrillators in left ventricular systolic dysfunction. Evid Rep Technol Assess. 2007:1.

14. Leyva F, Foley PW, Chalil S, et al. Cardiac resynchronization therapy guided by late gadoliniumenhancement cardiovascular magnetic resonance. J Cardiovasc Magn Reson. 2011; 13:29. [PubMed: 21668964]

15. Mele D, Agricola E, Monte AD, et al. Pacing transmural scar tissue reduces left ventricle reverse remodeling after cardiac resynchronization therapy. Int J Cardiol. 2012; 12:13.

16. Xu YZ, Cha YM, Feng D, et al. Impact of myocardial scarring on outcomes of cardiac resynchronization therapy: extent or location? J Nucl Med. 2012; 53:47. [PubMed: 22159181]

17. Dong YX, Powell BD, Asirvatham SJ, et al. Left ventricular lead position for cardiac resynchronization: a comprehensive cinegraphic, echocardiographic, clinical, and survival analysis. Europace. 2012; 14:1139. [PubMed: 22467754]

18. Strauss DG, Selvester RH. The QRS complex - a biomarker that "images" the heart: QRS scores to quantify myocardial scar in the presence of normal and abnormal ventricular conduction. $\mathrm{J}$ Electrocardiol. 2009; 42:85. [PubMed: 18790501]

19. Anderson WD, Wagner NB, Lee KL, et al. Evaluation of a QRS scoring system for estimating myocardial infarct size. 6 . Identification of screening criteria for non-acute myocardial infarcts. Am J Cardiol. 1988; 61:729. [PubMed: 3354433] 
20. Freye CJ, Wagner NB, Howe CM, et al. Evaluation of a QRS scoring system for estimating myocardial infarct size. 8. Specificity in a control-group with left-ventricular hypertrophy and proposal of a new scoring system for use with this confounding factor. J Electrocardiol. 1992; 25:19. [PubMed: 1531231]

21. Hindman NB, Schocken DD, Widmann M, et al. Evaluation of a QRS scoring system for estimating myocardial infarct size. 5. Specificity and method of application of the complete system. Am J Cardiol. 1985; 55:1485. [PubMed: 4003290]

22. Howe CM, Freye CJ, Wagner NB, et al. Evaluation of a QRS scoring system for estimating myocardial infarct size. 7. Specificity in a control-group with right ventricular hypertrophy due to mitral-stenosis. Am J Cardiol. 1988; 62:322. [PubMed: 2969674]

23. Ideker RE, Wagner GS, Ruth WK, et al. Evaluation of a QRS scoring system for estimating myocardial infarct size. 2. Correlation with quantitative anatomic findings for anterior infarcts. Am J Cardiol. 1982; 49:1604. [PubMed: 7081049]

24. Roark SF, Ideker RE, Wagner GS, et al. Evaluation of a QRS scoring system for estimating myocardial infarct size. 3. Correlation with quantitative anatomic findings for inferior infarcts. Am J Cardiol. 1983; 51:382. [PubMed: 6823852]

25. Wagner GS, Freye CJ, Palmeri ST, et al. Evaluation of a QRS scoring system for estimating myocardial infarct size. 1. Specificity and observer agreement. Circulation. 1982; 65:342. [PubMed: 7053893]

26. Ward RM, White RD, Ideker RE, et al. Evaluation of a QRS scoring system for estimating myocardial infarct size. 4. Correlation with quantitative anatomic findings for posterolateral infarcts. Am J Cardiol. 1984; 53:706. [PubMed: 6702617]

27. Elizari MV, Acunzo RS, Ferreiro M. Hemiblocks revisited. Circulation. 2007; 115:1154. [PubMed: 17339573]

28. Strauss DG, Selvester RH, Lima JA, et al. ECG quantification of myocardial scar in cardiomyopathy patients with or without conduction defects: correlation with cardiac magnetic resonance and arrhythmogenesis. Circ Arrhythm Electrophysiol. 2008; 1:327. [PubMed: 19808427]

29. Sweeney MO, van Bommel RJ, Schalij MJ, Borleffs CJ, Hellkamp AS, Bax JJ. Analysis of ventricular activation using surface electrocardiography to predict left ventricular reverse volumetric remodeling during cardiac resynchronization therapy. Circulation. 2010; 121:626. [PubMed: 20100970]

30. Loring Z, Chelliah S, Selvester RH, Wagner G, Strauss DG. A detailed guide for quantification of myocardial scar with the Selvester QRS score in the presence of electrocardiogram confounders. J Electrocardiol. 2011; 44:544. [PubMed: 21872001]

31. Wu KC, Weiss RG, Thiemann DR, et al. Late gadolinium enhancement by cardiovascular magnetic resonance heralds an adverse prognosis in nonischemic cardiomyopathy. J Am Coll Cardiol. 2008; 51:2414. [PubMed: 18565399]

32. Schmidt A, Azevedo CF, Cheng A, et al. Infarct tissue heterogeneity by magnetic resonance imaging identifies enhanced cardiac arrhythmia susceptibility in patients with left ventricular dysfunction. Circulation. 2007; 115:2006. [PubMed: 17389270]

33. Wu KC, Gerstenblith G, Guallar E, et al. Combined cardiac magnetic resonance imaging and Creactive protein levels identify a cohort at low risk for defibrillator firings and death. Circ Cardiovasc Imaging. 2012; 5:178. [PubMed: 22267750]

34. Selvester RH. Nomina anatomica contradicta revisited: especially as it relates to cardiac imaging and electrocardiology. J Electrocardiol. 2008:421. [author reply 423-424]. [PubMed: 18640687]

35. Cerqueira MD, Weissman NJ, Dilsizian V, et al. American Heart Association Writing Group on Myocardial Segmentation and Registration for Cardiac I: standardized myocardial segmentation and nomenclature for tomographic imaging of the heart: a statement for healthcare professionals from the Cardiac Imaging Committee of the Council on Clinical Cardiology of the American Heart Association. Circulation. 2002; 105:539. [PubMed: 11815441]

36. Allen TH, Krzywicki HJ, Roberts JE. Density fat, water and solids in freshly isolated tissues. J Appl Physiol. 1959; 14:1005. [PubMed: 13792786] 


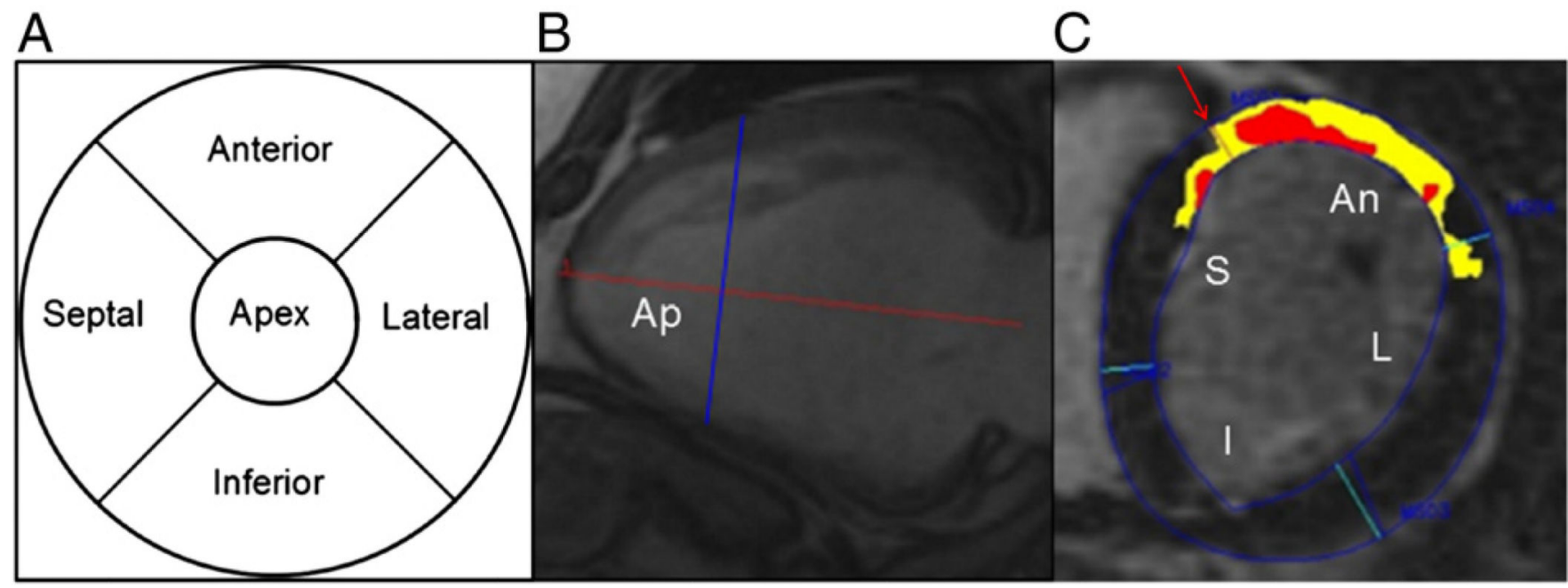

Fig. 1.

Division of the LV into five segments in the subdivision model used in conjunction with the LBBB version of the Selvester Scoring system. Panel A shows a bullseye plot of the LV divided into the five wall segments. The apical segment consists of the apical 1/3 of the LV. Panel B shows a long-axis CMR cine image depicting how the LV was divided into basal, middle and apical thirds. A base to apex line from the middle of the atrio-ventricular plane to the LV apex was drawn (horizontal red line). The apical segment consists of the apical third of the LV marked "Ap" left of the vertical blue line. Total LV length (horizontal red line) and short-axis slice thickness were used to determine which short-axis slices depicted the apical segment. Panel C shows a short-axis CMR-LGE image illustrating the subdivision of the two basal thirds of the LV into septal (S), anterior (An), lateral (L) and inferior (I) quadrants. The anterior RV insertion point (arrow) serves as the reference point to distinguish between the septal (S) and the anterior (An) wall segments. The other borders between the quadrants are spaced $90^{\circ}$ apart. The red area marks "core" scar and the yellow area marks "gray zone" scar. 


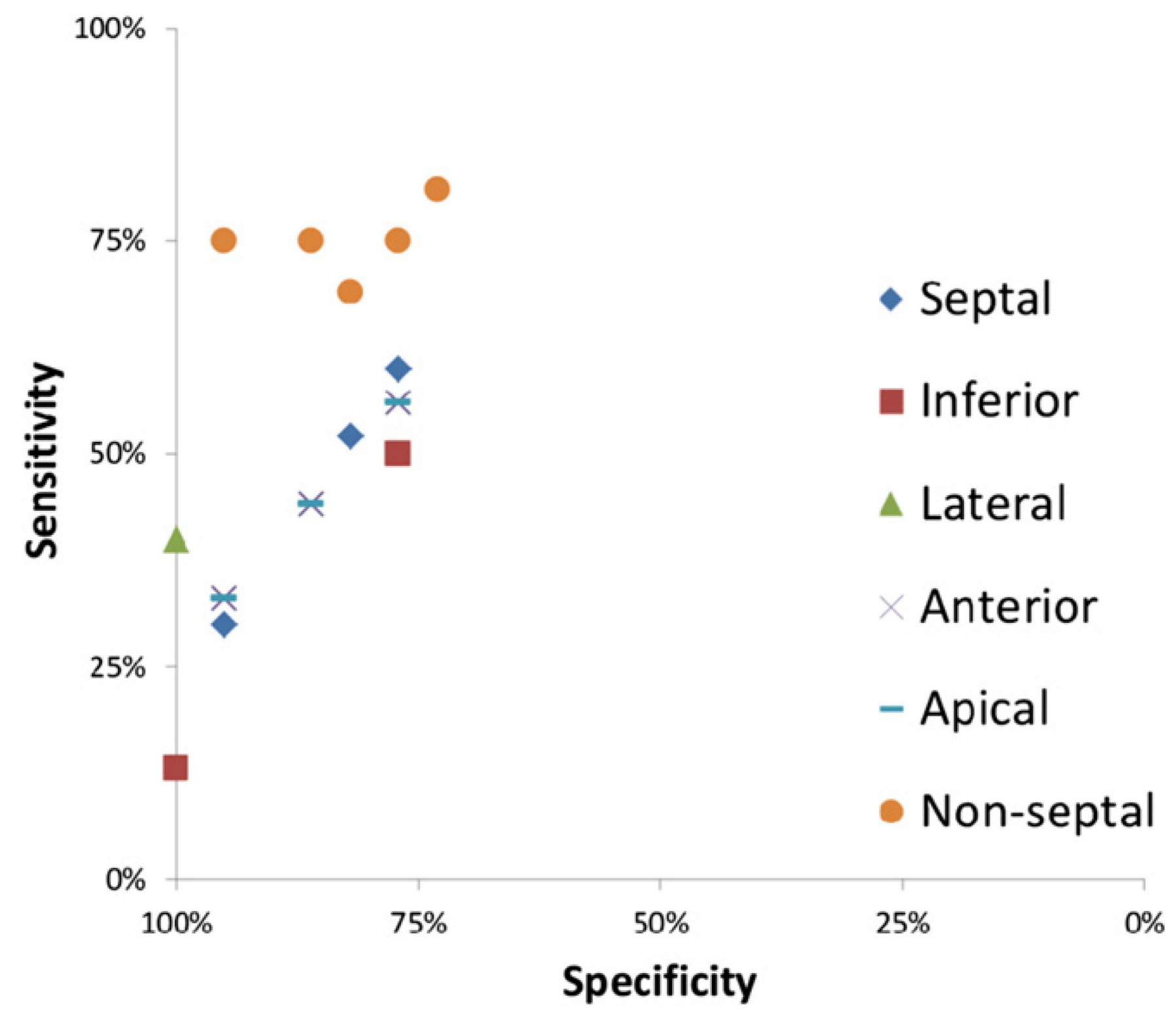

Fig. 2.

A receiver operator characteristics (ROC) diagram showing the specificity and sensitivity of the subsets of screening criteria identified for each LV segment for the different thresholds of required specificity: $95 \%, 90 \%, 85 \%, 80 \%, 75 \%$ and $70 \%$. Each segment is represented by its own symbol. Using the different specificity thresholds, two "candidate subsets" for screening criteria were identified for the septal segment, three or the anterior segment, one for the lateral segment, two for the inferior segment, three for the apical segment and five for the non-septal segments together. 

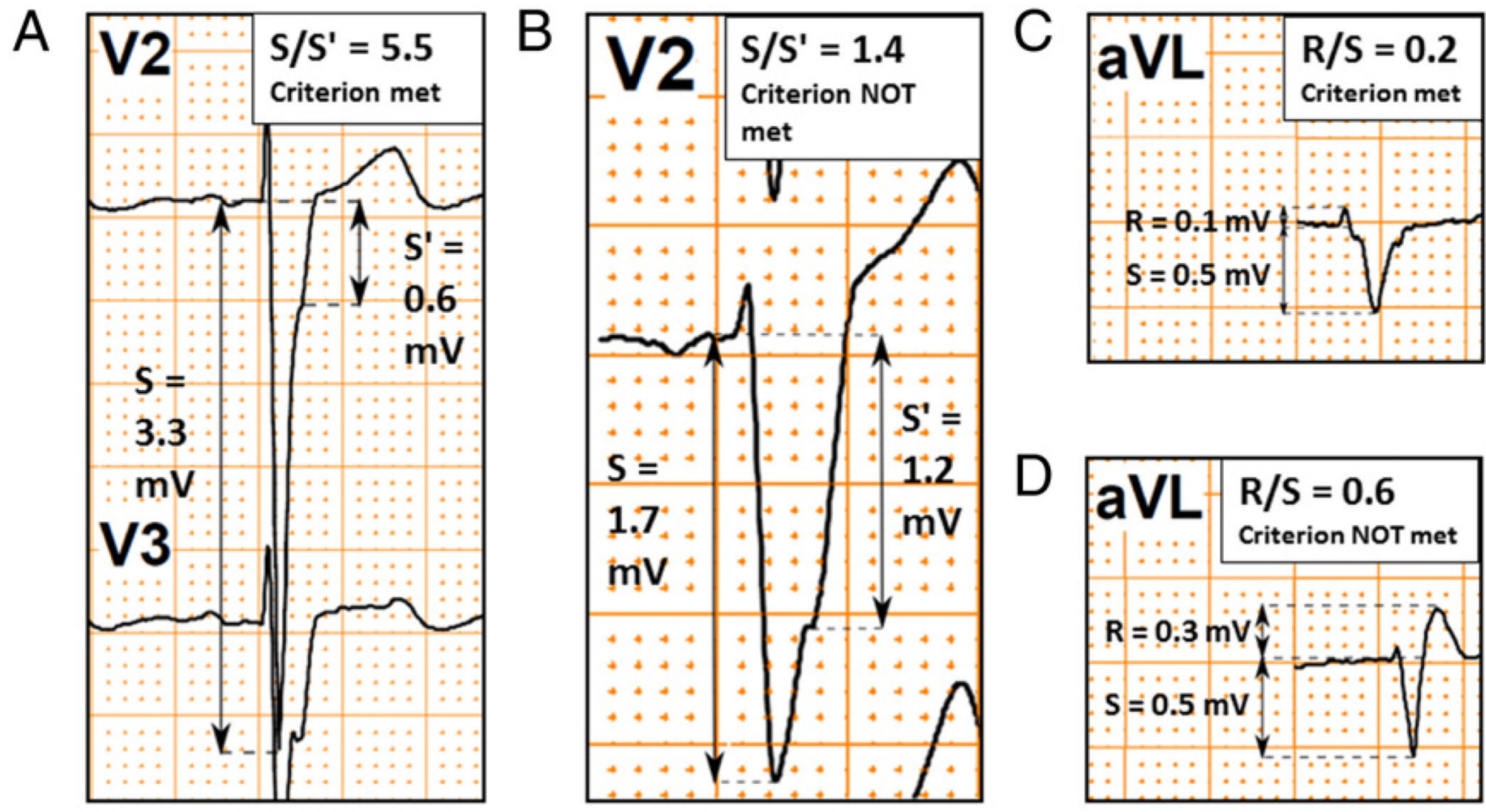

Fig. 3.

ECG examples of Selvester QRS score criteria in the identified subset for non-septal scar.

Panel A shows an example of the criterion $S / \mathrm{S}^{\prime} \geq 1.5$ in $\mathrm{V}_{2}$. In the context of this criterion $\mathrm{S}$ is defined as: "The first nadir, notch or beginning of the slur" 30 and $S^{\prime}$ is defined as "the second peak/nadir, notch, or end of the slur after the initial $40 \mathrm{~ms}$ of the QRS complex." 30 Panel B shows an example in which the criterion $S / S^{\prime} \geq 1.5$ in $V_{2}$ is not met. Panel C shows an example in which the " $\mathrm{R} / \mathrm{S} \leq 0.5$ in aVL" criterion is met. Importantly, the $\mathrm{R}$ and $\mathrm{S}$ amplitudes in the context of the "R/S" Selvester criteria are defined as the maximum positive and maximum negative amplitudes in the entire QRS complex, respectively. Consequently, if the $\mathrm{R}^{\prime}$ amplitude is greater than the $\mathrm{R}$ amplitude, the $\mathrm{R}^{\prime}$ amplitude is used instead to calculate the R/S ratio. Panel D depicts an example in which the high amplitude of the $\mathrm{R}^{\prime}$ waveform makes the "R/S $\leq 0.5$ in aVL" criterion negative. 


\section{Table 1}

The 45 individual LBBB Selvester QRS score criteria.

\begin{tabular}{|c|c|c|c|c|}
\hline Septal & Inferior & Lateral & Anterior & Apical \\
\hline $\mathrm{V}_{1}$ sep: NchInit40 & II: Q $\geq 40 \mathrm{~ms}$ & $\mathrm{~V}_{1}$ lat: $\mathrm{S} / \mathrm{S}^{\prime} \geq 2$ & I: R/Q $\leq 1.5$ & I: Any Q \\
\hline $\mathrm{V}_{1}$ sep: $\mathrm{R} \geq 0.3 \mathrm{mV}$ & II: $\mathbf{Q} \geq \mathbf{3 0} \mathbf{~ m s}$ & $\mathrm{V}_{1}$ lat: $\mathrm{S} / \mathrm{S}^{\prime} \geq 1.5$ & I: $\mathbf{R} / \mathrm{S} \leq \mathbf{1 . 5}$ & I: R/Q $\leq 1$ \\
\hline $\mathrm{V}_{1}$ sep: $\mathrm{R} \geq 30 \mathrm{~ms}$ & II: R/Q $\leq 0.5$ & $\mathrm{~V}_{1}$ lat: $\mathrm{S} / \mathrm{S}^{\prime} \geq 1.25$ & aVL: $Q \geq 50 \mathrm{~ms}$ & I: $\mathbf{R} / \mathbf{S} \leq \mathbf{1}$ \\
\hline $\mathrm{V}_{1}$ sep: $\mathrm{R} \geq 0.2 \mathrm{mV}$ & II: $\mathrm{R} / \mathrm{S} \leq 0.5$ & $\mathrm{~V}_{2}$ lat: $\mathrm{S} / \mathrm{S}^{\prime} \geq 2.5$ & aVL: Q $\geq 40 \mathrm{~ms}$ & I: $\mathrm{R} \leq 0.2 \mathrm{mV}$ \\
\hline$V_{1}$ sep: $R \geq 20 \mathrm{~ms}$ & aVF: Q $\geq 50 \mathrm{~ms}$ & $\mathrm{~V}_{2}$ lat: $\mathrm{S} / \mathrm{S}^{\prime} \geq 2$ & aVL: R/S $\leq 0.5$ & $V_{5}:$ any $Q$ \\
\hline$V_{2}$ sep: NchInit40 & aVF: Q $\geq 40 \mathrm{~ms}$ & $V_{2}$ lat: $S / S^{\prime} \geq 1.5$ & aVL: R/Q $\leq 0.5$ & $\mathrm{~V}_{5}: \mathrm{R} / \mathrm{R}^{\prime} \geq 2$ \\
\hline $\mathrm{V}_{2}$ sep: $\mathrm{R} \geq 0.4 \mathrm{mV}$ & aVF: R/S $\leq 0.5$ & & aVL: R/S $\leq \mathbf{1}$ & $\mathrm{V}_{5}: \mathrm{R} / \mathrm{R}^{\prime} \geq 1$ \\
\hline $\mathrm{V}_{2}$ sep: $\mathrm{R} \geq 30 \mathrm{~ms}$ & aVF: R/Q $\leq 0.5$ & & aVL: R/Q $\leq 1$ & $\mathrm{~V}_{5}: \mathrm{R} / \mathrm{S} \leq 2$ \\
\hline $\mathrm{V}_{2}$ sep: $\mathrm{R} \geq 0.3 \mathrm{mV}$ & & & & $\mathrm{V}_{5}: \mathrm{R} \leq 0.5 \mathrm{mV}$ \\
\hline \multirow[t]{5}{*}{$\mathrm{V}_{2}$ sep: $\mathrm{R} \geq 20 \mathrm{~ms}$} & & & & $\mathrm{~V}_{6}: \mathrm{Q} \geq 20 \mathrm{~ms}$ \\
\hline & & & & $\mathrm{V}_{6}: \mathrm{R} / \mathrm{R}^{\prime} \geq 2$ \\
\hline & & & & $\mathrm{V}_{6}: \mathrm{R} / \mathrm{R}^{\prime} \geq 1$ \\
\hline & & & & $\mathrm{V}_{6}: \mathrm{R} / \mathrm{S} \leq \mathbf{2}$ \\
\hline & & & & $\mathrm{V}_{6}: \mathrm{R} \leq 0.6 \mathrm{mV}$ \\
\hline
\end{tabular}

The LBBB Selvester QRS score criteria are arranged according to what segment they predict scar presence in. The individual criteria included in the identified optimal subsets of screening criteria for each of the five LV segments are highlighted.

Lat, lateral; NchInit 40, Notch in the initial $40 \mathrm{~ms}$ of the QRS complex; Sep, septal. 
Table 2

Study population characteristics $(n=39)$.

\begin{tabular}{|c|c|}
\hline & $\begin{array}{c}n(\%) \text { or } \\
\text { mean } \pm \text { SD }\end{array}$ \\
\hline \multicolumn{2}{|l|}{ NYHA class } \\
\hline 1 & $2(5)$ \\
\hline 2 & $15(39)$ \\
\hline 3 & $22(57)$ \\
\hline \multicolumn{2}{|l|}{ Gender } \\
\hline Male & $23(59)$ \\
\hline Female & $16(41)$ \\
\hline \multicolumn{2}{|l|}{ Ethnicity } \\
\hline Caucasian & $30(77)$ \\
\hline African American & $9(23)$ \\
\hline Age (y) & $61 \pm 10$ \\
\hline LVEF (mean \%) & $26 \pm 8$ \\
\hline Patients with scar $\geq 3 \%$ of the $\mathrm{LV}$ volume in at least 1 segment & $17(44)$ \\
\hline Total number of scarred segments (scar $\geq 3 \%$ of LV volume) & 41 \\
\hline Septal scar & $10(24)$ \\
\hline Inferior scar & $8(20)$ \\
\hline Lateral scar & $5(12)$ \\
\hline Anterior scar & $9(22)$ \\
\hline Apical scar & $9(22)$ \\
\hline Patients with any non-septal scar & $16(41)$ \\
\hline \multicolumn{2}{|l|}{ Etiology } \\
\hline Ischemic & $11(28)$ \\
\hline With scar $\geq 3 \%$ of LV & $11(28)$ \\
\hline Non-ischemic & $28(72)$ \\
\hline With scar $\geq 3 \%$ of LV & $6(15)$ \\
\hline \multicolumn{2}{|l|}{ Number of scarred segments } \\
\hline 1 & $4(10)$ \\
\hline 2 & $3(7)$ \\
\hline 3 & $9(21)$ \\
\hline 4 & $1(2)$ \\
\hline \multirow[t]{2}{*}{5} & $0(0)$ \\
\hline & Median (range) \\
\hline \multicolumn{2}{|l|}{ QRS duration (ms) } \\
\hline Entire cohort & $162(134-196)$ \\
\hline Male & $168(140-196)$ \\
\hline Female & $153(134-176)$ \\
\hline Ischemic & $164(134-196)$ \\
\hline Non-ischemic & $156(136-192)$ \\
\hline
\end{tabular}




\begin{tabular}{lc}
\hline & $\begin{array}{c}\boldsymbol{n}(\%) \text { or } \\
\text { mean } \pm \text { SD }\end{array}$ \\
\hline Scarred & $162(134-196)$ \\
Non-scarred & $158(136-180)$ \\
\hline
\end{tabular}

NYHA, New York Heart Association; LVEF, center ventricular ejection fraction; LV, center ventricle. 


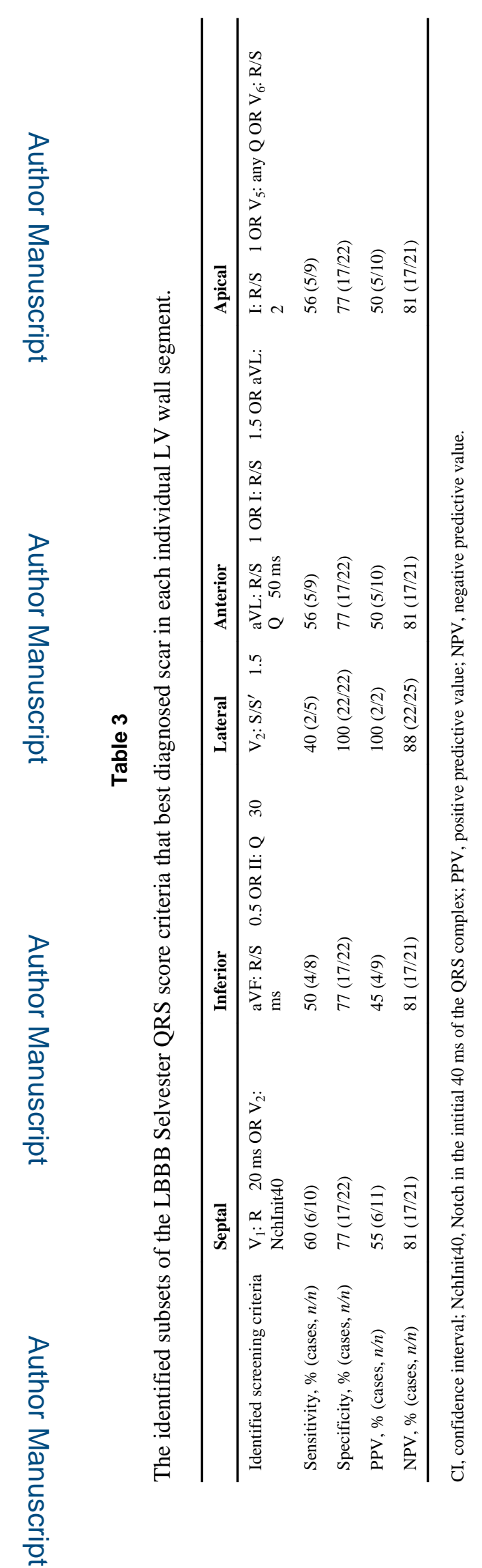

J Electrocardiol. Author manuscript; available in PMC 2015 May 22. 


\section{Table 4}

Diagnostic performance of identified screening criteria for any non-septal scar.

\begin{tabular}{lll}
\hline & $\begin{array}{l}\text { Individual sensitivity, } \\
\% \text { (cases, } \boldsymbol{n} / \boldsymbol{n})\end{array}$ & $\begin{array}{l}\text { Individual specificity, } \\
\boldsymbol{\%}(\text { cases, } \boldsymbol{n} / \boldsymbol{n})\end{array}$ \\
\hline $\mathrm{V}_{2}: \mathrm{S} / \mathrm{S}^{\prime} \geq 1.5 \mathrm{OR}$ & $31(5 / 16)$ & $100(22 / 22)$ \\
$\mathrm{I}: \mathrm{R} / \mathrm{S} \leq 1 \mathrm{OR}$ & $19(3 / 16)$ & $95(21 / 22)$ \\
$\mathrm{aVL}: \mathrm{R} / \mathrm{S} \leq 0.5 \mathrm{OR}$ & $13(2 / 16)$ & $100(22 / 22)$ \\
II: Q $\geq 30 \mathrm{~ms}$ OR & $13(2 / 16)$ & $100(22 / 22)$ \\
aVF: Q $\geq 40 \mathrm{~ms}$ & $13(2 / 15)$ & $100(22 / 22)$ \\
& & Cumulative diagnostic performance \\
\hline Sensitivity \% [95\% CI] (cases, $n / n)$ & $75[51-90](12 / 16)$ \\
Specificity \% [95\% CI] (cases, $n / n)$ & $95[78-99](21 / 22)$ \\
PPV \% [95\% CI] (cases, $n / n)$ & $92[67-99](12 / 13)$ \\
NPV \% [95\% CI] (cases, $n / n)$ & $84[65-94](21 / 25)$ \\
\hline
\end{tabular}

CI, confidence interval; PPV, positive predictive value; NPV, negative predictive value. 